\title{
DISCUSSION
}

\section{Determination of liquid limit from equilibrium sediment volume}

\author{
K. PRAKASH and A. SRIDHARAN (2002). Géotechnique 52, No. 9, 693-696
}

T. S. Nagaraj and D. J. DeGroot, University of Massachusetts, Amherst, USA

The authors present an intriguing insight into the waterholding capacity of clays. They propose a method for determining the liquid limit from equilibrium sediment volume. This is appropriate as the equilibrium sediment state is due to an effective stress level of a definite value of matrix suction. This is borne out of the authors' statement regarding the use of soil moisture tension by Russell \& Mickle (1970) as one of the alternative methods for determining the liquid limit. In fact, in the initial period of analysis and use, the liquid limit was regarded mainly as a physical parameter of clays and used primarily for classification of fine-grained soils. However, a significant step towards the use of the liquid limit as an engineering property can be attributed to the work of Skempton (1944) for assessment of the compression index of clays from their liquid limit water content. Nagaraj \& Srinivasa Murthy (1983) subsequently examined this from a micromechanistic viewpoint. The liquid limit has the attributes of an engineering parameter reflecting shear strength and compressibility at that water content due to a low but not negligible value of effective stress (Nagaraj et al., 1993). As such, it is a valuable parameter for accessing soil behaviour and the in-situ nature of soil deposits.

The authors' test procedure, which is simple to perform and apparatus-independent, can be used by engineers to determine the equilibrium (taken as $24 \mathrm{~h}$ ) sediment void ratio $e_{\mathrm{s}}$ from the measured sediment volume, dry weight of the sample, and the measured or assumed specific gravity. Values of $e_{\mathrm{s}}$ can be used as a normalising parameter for grouping soils into different states (e.g. normally or overconsolidated, aged or naturally cemented) with reference to an intrinsic state line (ISL) similar to that developed by Nagaraj et al. (1994) and Nagaraj and Miura (2001) using the liquid limit void ratio $e_{\mathrm{L}}$. Such a framework allows for the assessment of engineering behaviour such as compressibility, shear strength and permeability.

The concept of using $e_{\mathrm{S}}$ as an alternative parameter to $e_{\mathrm{L}}$ in obtaining the reference state of clays was presented by the first discusser and his co-workers in 1984 (Nagaraj et al., 1984). Table 1 summarises data for four Indian soils tested by Nagaraj et al. (1984) - three residual soils and one marine soil. The liquid limit values were determined using the fall cone method on oven-dry samples. The liquid limit void ratio was computed as equal to $w_{\mathrm{L}} G$, and the sediment void ratio was determined from the measured $24 \mathrm{~h}$ sediment volume using a procedure similar to that presented by the authors.

The relationship between equilibrium sediment volume and liquid limit void ratio for the data in Table 1 is

$$
e_{\mathrm{s}}=1.76 e_{\mathrm{L}}
$$

Figure 4(a) plots the one-dimensional compression paths for these four clays starting from a remoulded state. Nagaraj et al. (1984) normalised these data by $e_{\mathrm{L}}$ and found a unique relationship of the form (Fig. 4(b))

$$
\frac{e}{e_{\mathrm{L}}}=1.23-0.276 \log \sigma_{\mathrm{v}}^{\prime}
$$

with a goodness-of-fit $r^{2}=0.976$ for number of data points $n=24$.

Normalising the consolidation data by $e_{\mathrm{s}}$ rather than $e_{\mathrm{L}}$ gives the following relationship (Fig. 4(c))

$$
\frac{e}{e_{\mathrm{s}}}=0.69-0 \cdot 149 \log \sigma_{\mathrm{v}}
$$

with $r^{2}=0.980$

Figure 5(a) plots void ratio against permeability for the four soils listed in Table 1. Again, normalisation by $e_{\mathrm{L}}$ (Fig. 5(b)) produces a unique relationship as presented by Nagaraj et al. (1984)

$$
\frac{e}{e_{\mathrm{L}}}=2 \cdot 23+0 \cdot 204 \log k_{\mathrm{V}}
$$

with $n=24$ and $r^{2}=0.974$. Normalising these data by $e_{\mathrm{s}}$ gives the following relationship (Fig. 5(c))

$$
\frac{e}{e_{\mathrm{s}}}=1 \cdot 25+0 \cdot 112 \log k_{\mathrm{v}}
$$

with $r^{2}=0.980$.

These data show that the liquid limit void ratio as determined by conventional tests and the equilibrium sediment void ratio result in unique relationships between normalised void ratio $\left(e / e_{\mathrm{L}}\right.$ or $\left.e / e_{\mathrm{S}}\right)$ and compressibility and permeability. In all cases the resulting equations are linear in semi-log space with very high $r^{2}$ values. However, measurement of the equilibrium sediment volume, as proposed by the authors, is simple to perform and apparatus-independent, unlike the traditional liquid limit test equipment and procedures. Thus the equilibrium sediment volume procedure, when coupled with reference states like those presented in Figs 4(c) and 5(c), provide a convenient framework for grouping soils of similar states and behaviour. That is, the

Table 1. Summary of soil properties

\begin{tabular}{l|c|c|c|c|c|c}
\hline Soil & $\begin{array}{c}\text { Liquid limit: } \\
\%\end{array}$ & $\begin{array}{c}\text { Plastic limit: } \\
\%\end{array}$ & PI: \% & $\begin{array}{c}\text { Specific gravity, } \\
G\end{array}$ & $\begin{array}{c}\text { Liquid limit void ratio, } \\
e_{\mathrm{L}}\end{array}$ & $\begin{array}{c}\text { Sediment void ratio, } \\
e_{\mathrm{S}}\end{array}$ \\
\hline Red soil & 50 & 27 & 23 & 2.65 & $1 \cdot 32$ & 2.31 \\
Brown soil & 62 & 31 & 31 & 2.63 & 1.62 & 2.85 \\
Black cotton soil & 84 & 47 & 37 & 2.68 & 2.25 & 3.96 \\
Marine soil & 106 & 47 & 59 & 2.64 & 2.79 & 4.92 \\
\hline
\end{tabular}




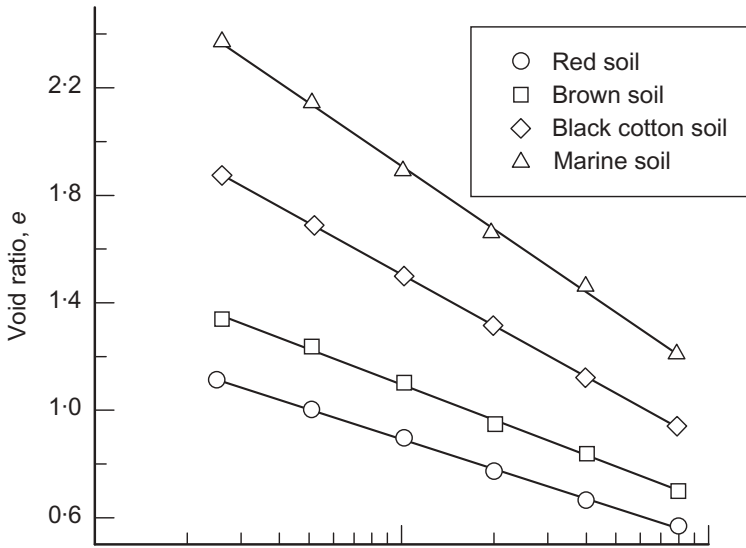

(a)

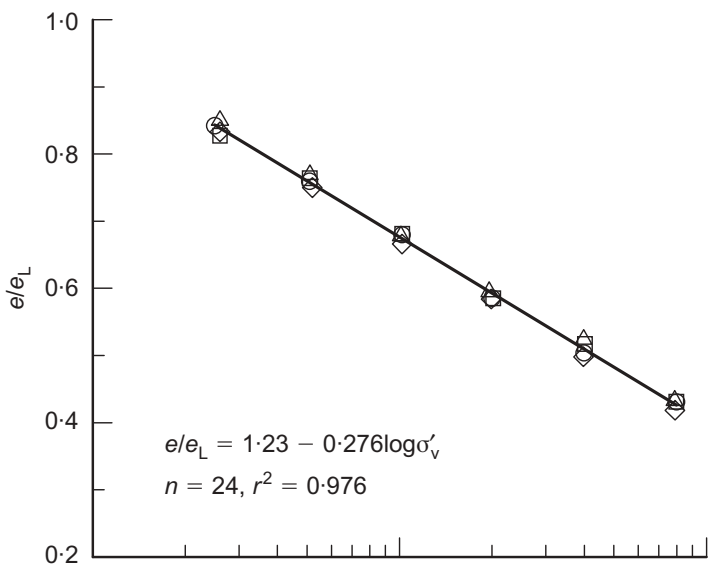

(b)

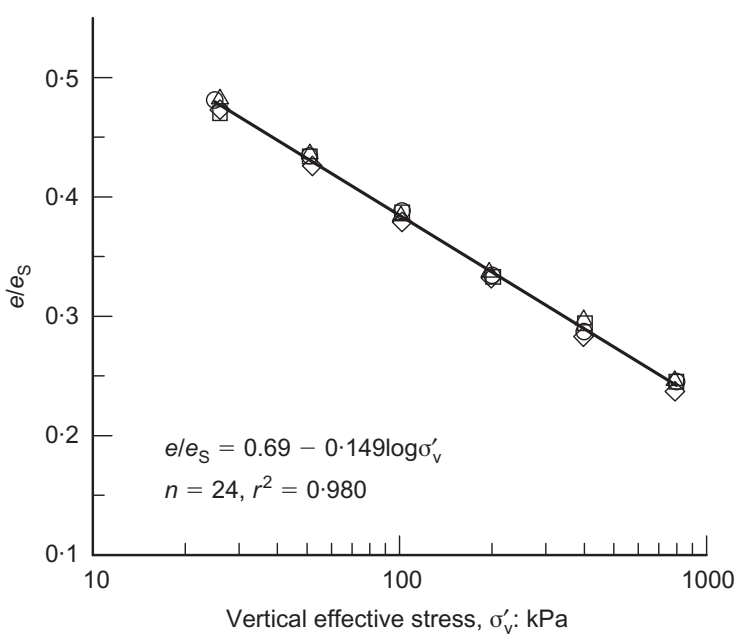

(c)

Fig. 4. Consolidation relationships: (a) void ratio, $e$; (b) normalised liquid limit void ratio, e/e $e_{\mathrm{L}}$; (c) normalised sediment volume void ratio, e/es

intrinsic state line framework based on $e_{\mathrm{L}}$, as originally developed by Nagaraj et al. (1984), is readily extended to the use of $e_{\mathrm{s}}$.

Although the data presented here are limited to four soils, they do span a fairly wide range of void ratios at the liquid limit $\left(e_{\mathrm{L}}=1.32-2.79\right)$ and at the sediment equilibrium state $\left(e_{\mathrm{s}}=2 \cdot 31-4.92\right)$. However, the focus of this discussion is not on the specific relationships suggested but rather on the phenomenological model possible with equilibrium sediment void ratio. The possibility of refining the constants in equa-

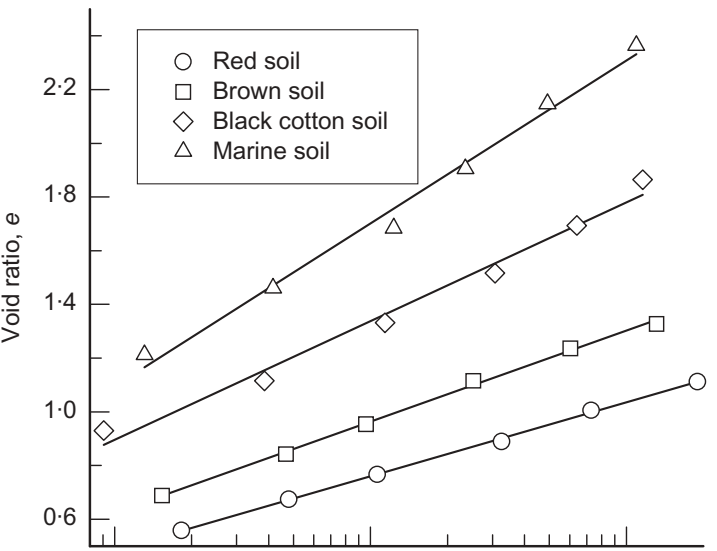

(a)

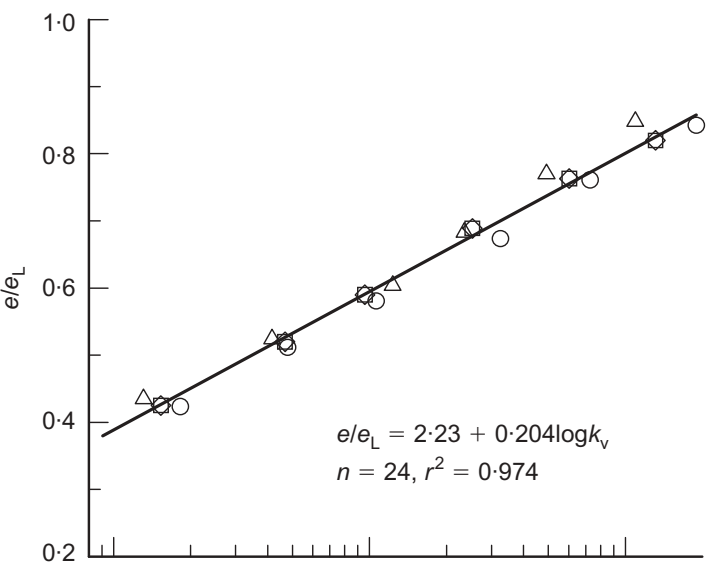

(b)

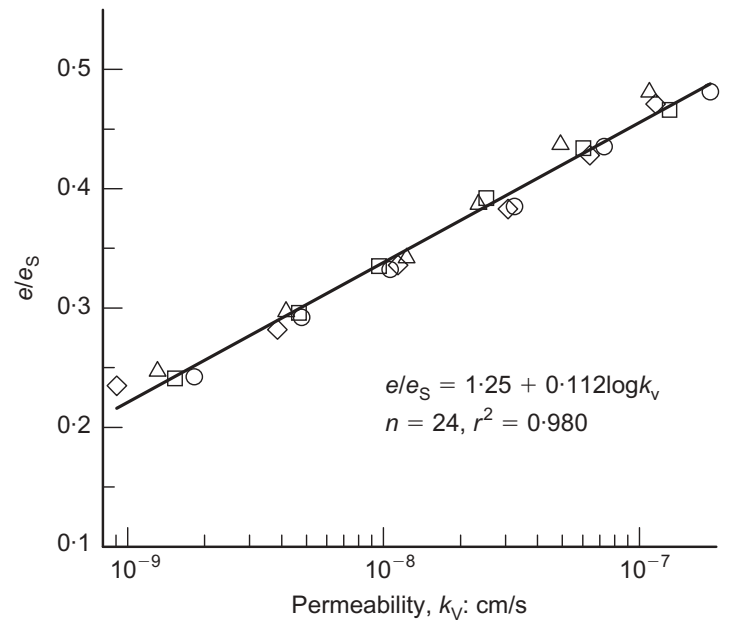

(c)

Fig. 5. Permeability relationships: (a) void ratio, $e$; (b) normalised liquid limit void ratio, e/e $\mathrm{L}$; (c) normalised sediment volume void ratio, $e / e_{\mathrm{S}}$

tions (11) and (13) remains as and when more data become available.

Although the data presented in Table 1 are for oven-dry soils (the tests were conducted in 1984), it is preferred that future sediment volume tests be conducted on samples that are not oven dried. The authors note such a restriction for marine soils, but in fact a variety of other soils can also be adversely influenced by the oven drying process (e.g. Pandian et al., 1993). Thus a prudent approach would be to avoid using oven-dry samples and simply calculate the sediment volume as presented by the authors in equation 
(8). This does prolong the test, as the water content of the sample after sedimentation needs to be measured, but it removes any uncertainty about the influence of oven drying.

\section{Authors' reply}

The discussers have explained the use of the void ratio at equilibrium sediment volume as a normalising parameter for grouping soils into different states and for the assessment of engineering behaviour such as compressibility, shear strength and permeability. The authors are aware of the contribution of the senior discusser and his co-workers in using the void ratio at liquid limit for the prediction of engineering behaviour of fine-grained soils. Replacing of void ratio at liquid limit by void ratio at equilibrium sediment volume is a simple possibility. The authors, however, do feel that the engineering behaviour of fine-grained soils cannot be so simply predicted with a single parameter, except in ideal situations.

\section{REFERENCES}

Nagaraj, T. S. \& Miura, N. (2001). Soft clay behaviour: Analysis and assessment. Rotterdam: Balkema.

Nagaraj, T. S. \& Srinivasa Murthy, B. R. (1983). Rationalization of Skempton's compressibility equation. Géotechnique 33, No. 4, 433-443.

Nagaraj, T. S., Pandian, N. S. \& Narasimha Raju, P. S. R. (1984). Sediment void ratio as a potential parameter in the analysis of soil behaviour. Proc. Indian Geotech. Conf. 1984, Calcutta, $49-52$.

Nagaraj, T. S., Pandian, N. S. \& Narasimha Raju, P. S. R. (1993). Stress state permeability relationships for fine-grained soils. Géotechnique 43, No. 2, 333-336.

Nagaraj, T. S., Srinivasa Murthy, B. R. \& Vatsala, A. (1994). Analysis and prediction of soil behaviour. New Delhi: Wiley Eastern.

Pandian, N. S., Nagaraj, T. S. \& Sivakumar Babu, G. L. (1993). Behaviour of tropical clays. Part I: Index properties and microstructural considerations. J. Geotech. Engng, ASCE 119, No. 5, $826-839$.

Skempton, A. W. (1944). Notes on compressibility of clays. Q. J. Geol. Soc., London 119-135. 